\title{
Video-assisted loboisthmectomy by the subclavicular approach. A case report
}

\author{
Virgilijus Beiša ${ }^{1}$, Audrius Sileikis ${ }^{1}$, Vitalijus Eismontas ${ }^{2}$, Kęstutis Strupas ${ }^{1}$ \\ ${ }^{1}$ Medical Faculty, Center of Abdominal Surgery, Vilnius University, Lithuania \\ ${ }^{2}$ Abdominal and Endocrine Surgery Department, Klaipeda University Hospital, Lithuania
}

Videosurgery Miniinv 2012; 7 (3): 206-209

DOI: 10.5114/wiitm.2011.27579

\begin{abstract}
The main advantage of minimally invasive thyroidectomy is a good cosmetic effect. Minimally invasive video-assisted thyroidectomy (MIVAT) is performed without gas insufflation in contrast to endoscopic thyroidectomy. In general, MIVAT is carried out through an incision in the middle part of the neck, not covered with clothes. The MIVAT thyroid lobectomy can also be done through the subclavicular approach. We describe a case of a 19-year-old female patient with a tumour of the left side of the neck. Thyroid ultrasound scan (UST) with thyroid fine-needle aspiration and cytological examination (FNAC) were performed. Thyroid-stimulating hormone (TSH), free triiodothyronine (FT3) and anti-tyreoperoxidase (ATPO) were checked. Video-assisted hemithyroidectomy was performed through an incision below the left clavicle. Intraoperative pathology examination of the specimen was carried out. The UST showed a solitary $13 \mathrm{~mm} \times$ $23 \mathrm{~mm}$ nodule in the left lobe of the thyroid, the FNAC showed benign pathology. Thyroid function tests were normal (TSH $0.90 \mathrm{mIU} / \mathrm{l}$; FT3 $4.70 \mathrm{pmol} / \mathrm{l})$. Video-assisted hemithyroidectomy was done through the incision below the left clavicle. Histopathological examination proved thyroid hyperplasia nodosum. There were no intra-or postoperative complications. The patient was discharged on the second day. Clinical and cosmetic outcomes 2 months after surgery were good. Minimally invasive video-assisted thyroid lobectomy performed via the subclavicular area is feasible and provides good cosmetic outcomes.
\end{abstract}

Key words: thyroid surgery, video-assisted thyroidectomy, minimally invasive thyroidectomy.

\section{Introduction}

The golden age of minimally invasive surgery started a few years after the introduction of laparoscopy to abdominal surgery. Similarly but a bit later, development of minimally invasive techniques in thyroid and parathyroid surgery started.

In 1996 Gagner [1] published the first report on endoscopic neck surgery - subtotal parathyroidectomy. In 1998 Bellantone et al. [2] reported a videoassisted thyroid lobectomy. In 1999, Miccoli et al. [3, 4], who were among the earliest pioneers of minimally invasive video-assisted thyroid surgery (MIVAT) in Europe, published a paper on the resection of small thyroid nodules by minimally invasive means. In 2000, Ikeda and co-authors published a paper on the armpit approach in MIVAT and Ohgami et al. wrote about the breast approach $[5,6]$. The advantages of minimally invasive thyroid surgery compared to the classic approach include reduced blood loss, decreased postoperative pain, and less discomfort and neck paraesthesia [6]. One of the advantages of such an approach considered by patients, particularly by women, is improved postoperative cosmetic outcome [6]. 
The aim of this study was to assess feasibility and to prove better cosmesis with MIVAT thyroid lobectomy via the subclavicular approach.

\section{Case report}

A 19-year-old female patient was referred to us due to a visible tumour and discomfort in the left side of the neck. Thyroid ultrasound scan (UST), blood tests (thyroid-stimulating hormone (TSH), free triiodothyronine (FT3) and anti-tyreoperoxidase (ATPO)) as well as fine-needle aspiration biopsy with cytology (FNAC) were performed. Intraoperative pathological examination of the excised specimen was carried out.

Thyroid ultrasound scan showed the right thyroid lobe of $13.8 \mathrm{~mm} \times 15 \mathrm{~mm} \times 36.4 \mathrm{~mm}$ with volume of $3.95 \mathrm{~cm}^{3}$, with normal echogenicity and no pathological findings. The left lobe was $20.3 \mathrm{~mm} \times 17 \mathrm{~mm} \times 38 \mathrm{~mm}$ with volume of $6.75 \mathrm{~cm}^{3}$. There was an isoechogenic node of $13 \mathrm{~mm} \times 23 \mathrm{~mm}$ occupying the majority of the left lobe and growing into the isthmus, with cystic degeneration and increased hypoechogenicity. There was no neck lymphadenopathy. Thyroid function was normal with the following values: $\mathrm{TSH}=0.90 \mathrm{mIU} / \mathrm{l}$, $\mathrm{FT} 3=4.70 \mathrm{pmol} / \mathrm{l}$, ATPO $=0.00 \mathrm{IU} / \mathrm{ml}$. The FNAC showed changes typical for benign thyroid nodes.

In the presented case the main indications for surgery were the patient's discomfort and poor cosmesis. In order to optimize the cosmetic outcome, MIVAT with incision in the subclavicular area was chosen. The final pathological diagnosis was nodular hyperplasia of thyroid with benign macropapillary formations.

A $3 \mathrm{~cm}$ incision via skin, subcutaneous tissue and platysma was carried out below the left clavicle. The

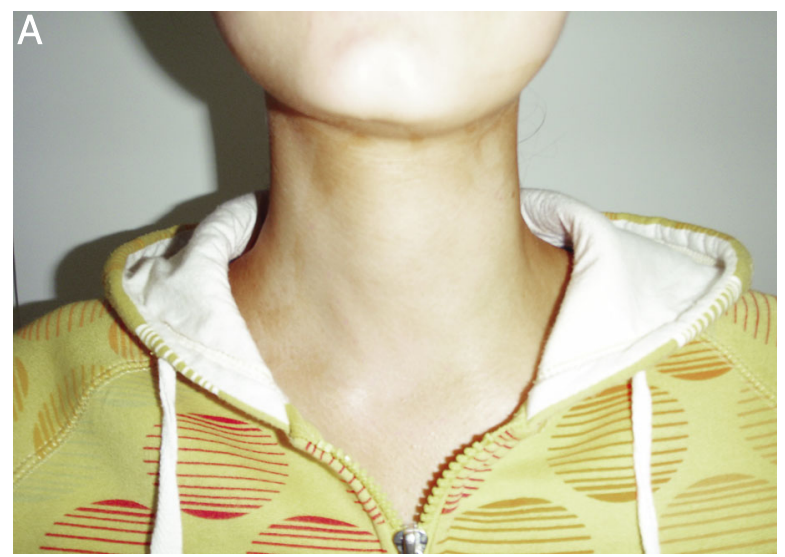

Figure 2 A-B. Second postoperative day left sternocleidomastoid muscle was dissected. We used a 30-degree, $5 \mathrm{~mm}$ Karl Storz scope, $6 \mathrm{~cm}$ long urological hook, and video-assisted surgery instruments proposed by Miccoli $(19 \mathrm{~cm}$ long Miccoli blunt suction elevator with stilettos and finger covered hole, $19 \mathrm{~cm}$ long and $2 \mathrm{~mm}$ in diameter Miccoli blunt elevator). The anterior neck muscles were dissected from the inner side of the sternocleidomastoid muscle. Intraoperative findings confirmed a large nodule almost completely filling the left thyroid lobe. The lateral (Kocher) thyroid vein was coagulated and cut using a harmonic scalpel. The left inferior thyroid artery and, afterwards, the superior thyroid artery were with the harmonic scalpel. The thyroid lobe was separated from the trachea and removed while preserving both parathyroid glands and the left recurrent laryngeal nerve thanks to the use of the har-

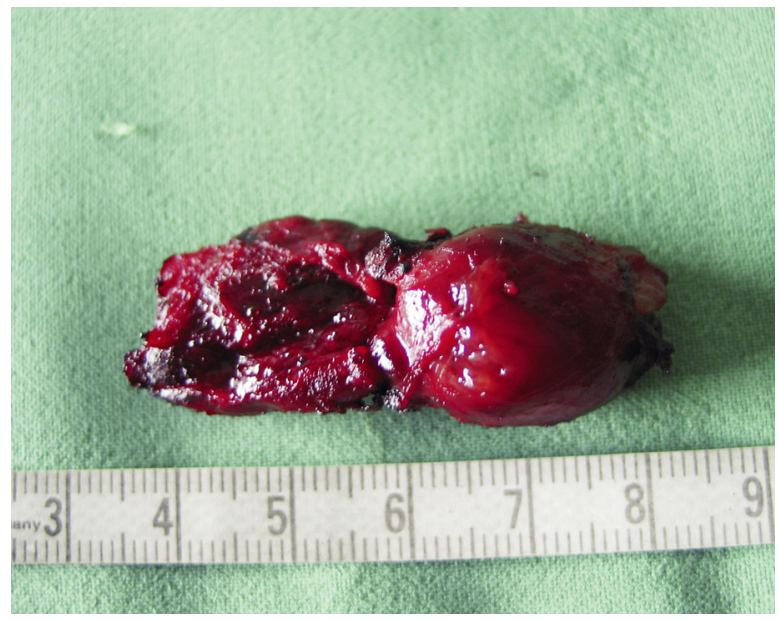

Figure 1. The specimen - left thyroid lobe

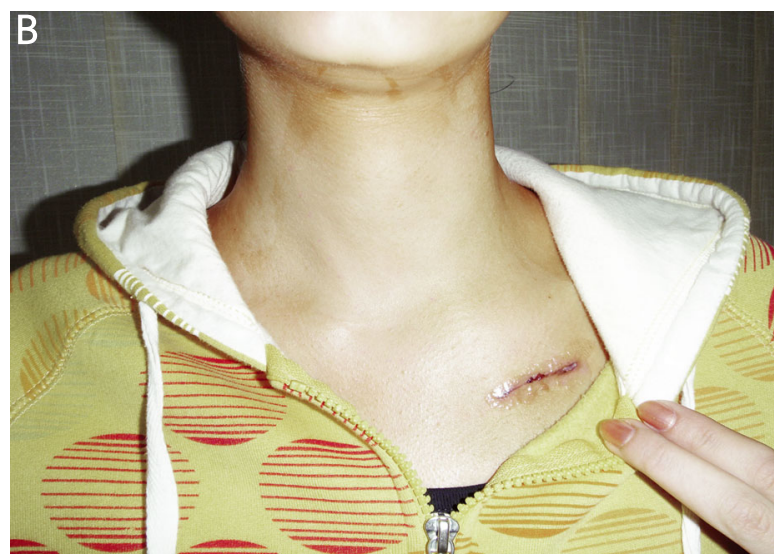




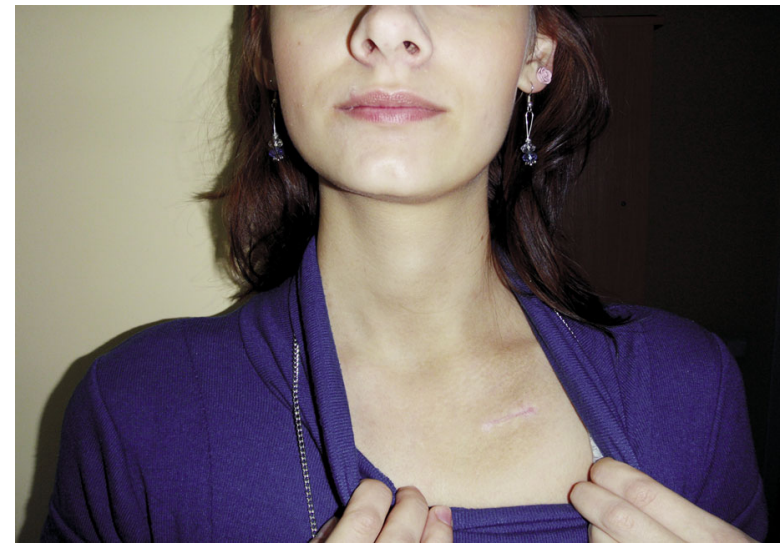

Figure 3. Two months after surgery

monic scalpel (Figure 1). Intraoperative pathology examination confirmed nodular thyroid hyperplasia. There was no drain left. The skin was closed with intracutaneous 5.0 absorbable colourless monocryl suture. The weight of the removed lobe was $7.6 \mathrm{~g}$. Operating time was $110 \mathrm{~min}$.

There were no intra- or postoperative complications. Both voice folds were adequately mobile on the ENT assessment on the first postoperative day. The patient was discharged home on the second postoperative day after assessment (Figure 2 A-B). The final pathology report provided the diagnosis of nodular thyroid hyperplasia with benign macropapillary formations. During the 2-month follow-up the patient remained in a good condition. The scar below the left clavicle was barely visible, with a length of $2.5 \mathrm{~cm}$ (Figure 3).

\section{Discussion}

The advantages of all minimally invasive procedures are similar and include reduced postoperative pain, smaller blood loss, and faster social reintegration [6-8]. In thyroid surgery, the major advantage of a minimally invasive approach versus traditional is a better cosmetic effect [1, 5-7, 9-12]. The majority of patients ( 9 of 10) with thyroid disorders are women. Traditionally, the thyroidectomy incision is made in the visible, uncovered area of the neck. The best cosmetic effect following endoscopic thyroidectomy can be achieved via the axillary or breast approach, but the popularity of these operations is not high because of the need for special instruments and a long learning period [7-9, 13, 14]. The most common cause of poor cosmesis after conventional thyroidec- tomy is a scar that moves during swallowing due to adhesion of the platysma to the skin and the front neck muscles after a large dissection of tissues. After the MIVAT surgery, there are no adhesions between the scar and the front neck muscles. There are also reduced sensory disturbances and discomfort in the neck in comparison to traditional thyroidectomy [15, 16]. The incision hidden in the subclavicular area that is usually covered with clothes further improves the cosmetic effect of the MIVAT. Importantly, only one lobe of the thyroid can be removed via the incision in the subclavicular area; thus patients with benign thyroid changes should be selected and limited to those suitable for the MIVAT operation who fulfil specific conditions: thyroid volume up to $25 \mathrm{ml}$, node size up to $30 \mathrm{~mm}$, no previous thyroid surgery and no autoimmune thyroiditis.

\section{Conclusions}

Thyroid lobectomy performed with the use of video-assisted methods via the subclavicular area that is usually covered with clothes is feasible and provides a good cosmetic effect in carefully selected patients.

\section{References}

1. Gagner M. Endoscopic subtotal parathyroidectomy in patients with primary hyperparathyroidism. Br J Surg 1996; 83: 875.

2. Bellantone R, Lombardi CP, Raffaelli M, et al. Minimally invasive, totally gasless video-assisted thyroid lobectomy. Am J Surg 1999; 177: 342-3.

3. Miccoli P, Berti P, Raffaelli M, et al. Comparison between minimally invasive video-assisted thyroidectomy and conventional thyroidectomy: a prospective randomised study. Surgery 2001; 130: 1039-43.

4. Miccoli P, Berti P, Conte M, et al. Minimally invasive surgery for small thyroid nodules: preliminary report. I Endocrinol Invest 1999; 22: 849-51.

5. Ikeda Y, Takami H, Sasaki Y, et al. Endoscopic neck surgery by the axillary approach. J Am Coll Surg 2000; 191: 336-40.

6. Ohgami M, Ishii S, Arisawa Y, et al. Scarless endoscopic thyroidectomy: breast approach for better cosmesis. Surg Laparosc Endosc Percutan Tech 2000; 10: 1-4.

7. Jiang Z, Zhang W, Jiang D, et al. Clinical benefits of scarless endoscopic thyroidectomy: an expert's experience. World I Surg 2010; 35: 553-7.

8. Cho YU, Park IJ, Choi KH, et al. Gasless endoscopic thyroidectomy via an anterior chest wall approach using a flap-lifting system. Yonsei Med J 2007; 48: 480-7.

9. Liu S, Qiu M, Jiang DZ, et al. The learning curve for endoscopic thyroidectomy: a single surgeon's experience. Surg Endosc 2009; 23: 1802-6. 
10. Slotema ET, Sebag F, Henry JF. What is the evidence for endoscopic thyroidectomy in the management of benign thyroid disease? World J Surg 2008; 32: 1325-32.

11. Bellantone R, Lombardi CP, Bossola M, et al. Video-assisted vs conventional thyroid lobectomy - a randomised trial. Arch Surg 2002; 137: 301-4.

12. Lombardi CP, Raffaelli M, Princi P, et al. Safety of video-assisted thyroidectomy versus conventional surgery. Head Neck 2005; 27: 58-64.

13. Sasaki A, Nakajima J, Ikeda K, et al. Endoscopic thyroidectomy by the breast approach: a single institution's 9-year experience. World J Surg 2008; 32: 381-5.

14. Beisa V, Kazanavicius D, Skrebunas A, et al. Prognosis of thyroid function after hemithyroidectomy. Cent Eur J Med 2011; 6: 152-7.

15. Ikeda Y, Takami H, Sasaki Y, et al. Comparative study of thyroidectomies. Endoscopic surgery versus conventional open surgery. Surg Endosc 2002; 16: 1741-5.

16. Ikeda Y, Takami H, Sasaki Y, et al. Clinical benefits in endoscopic thyroidectomy by the axillary approach. J Am Coll Surg 2003; 196: 189-95. 